\title{
Squaramide-Based Supramolecular Materials for Three-Dimensional Cell Culture of Human Induced Pluripotent Stem Cells and Their Derivatives
}

Ciqing Tong, ${ }^{\dagger}$ Tingxian Liu, $^{\dagger}$ Victorio Saez Talens, ${ }^{\dagger}$ Willem E. M. Noteborn, ${ }^{\dagger}$ Thomas H. Sharp, Marco M. R. M. Hendrix, ${ }^{\S}$ Ilja K. Voets, ${ }^{\S}{ }^{\circledR}$ Christine L. Mummery, ${ }^{\#}$ Valeria V. Orlova, ${ }^{\#}$ and Roxanne E. Kieltyka*, ${ }^{*}$

${ }^{\dagger}$ Department of Supramolecular and Biomaterials Chemistry, Leiden Institute of Chemistry, Leiden University, P.O. Box 9502,2300 RA, Leiden, The Netherlands

${ }^{\ddagger}$ Department of Molecular Cell Biology, Section Electron Microscopy, Leiden University Medical Center, 2300 RC, Leiden, The Netherlands

${ }^{\S}$ Institute for Complex Molecular Systems, Eindhoven University of Technology, P.O. Box 513, 5600 MD, Eindhoven, The Netherlands

\#Department of Anatomy and Embryology, Leiden University Medical Center, Leiden University, Einthovenweg 20, 2333 ZC, Leiden, The Netherlands

Supporting Information
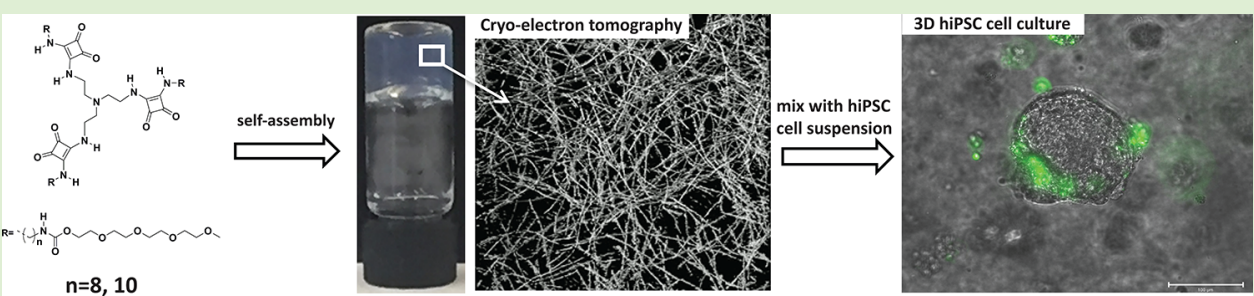

ABSTRACT: Synthetic hydrogel materials can recapitulate the natural cell microenvironment; however, it is equally necessary that the gels maintain cell viability and phenotype while permitting reisolation without stress, especially for use in the stem cell field. Here, we describe a family of synthetically accessible, squaramide-based tripodal supramolecular monomers consisting of a flexible tris(2-aminoethyl)amine (TREN) core that self-assemble into supramolecular polymers and eventually into selfrecovering hydrogels. Spectroscopic measurements revealed that monomer aggregation is mainly driven by a combination of hydrogen bonding and hydrophobicity. The self-recovering hydrogels were used to encapsulate NIH 3T3 fibroblasts as well as human-induced pluripotent stem cells (hiPSCs) and their derivatives in 3D. The materials reported here proved cytocompatible for these cell types with maintenance of hiPSCs in their undifferentiated state essential for their subsequent expansion or differentiation into a given cell type and potential for facile release by dilution due to their supramolecular nature.

\section{INTRODUCTION}

The surging interest in adaptive materials for a broad range of applications, from biomedicine to electronics, has invigorated the development of functional materials within the supramolecular polymer community. ${ }^{1-3}$ Because of their inherent noncovalent nature, supramolecular polymer materials can exhibit unique features in comparison to their covalent counterparts such as facile preparation, responsiveness, and self-healing. As biomaterials, their easy processing permits the mixing of numerous functionalized monomers with complex cargoes such as peptides, and their responsiveness to stimuli such as temperature, $\mathrm{pH}$, light, and enzymes opens the door to designer materials that can deliver therapeutic cargo, or as scaffolds for $3 \mathrm{D}$ cell culture. ${ }^{4-14}$ One particular area where supramolecular hydrogels can be especially useful is in the culture of human pluripotent stem cells (hPSCs), which are unique in their capacity to generate any body cell type. Human induced pluripotent stem cells (hiPSCs) have been shown to recapitulate all properties of human embryonic stem cells (hESCs) derived from preimplantation stage human embryos, but are instead derived from somatic cells obtained in a noninvasive manner by reprogramming with a set of transcription factors, thus overcoming ethical issues related to their embryonic counterparts. ${ }^{15,16}$ Excitingly, hiPSCs have the potential for decreased immunogenicity because they can be derived from autologous sources, but they require specific culture conditions to maintain their pluripotent state. ${ }^{17-20}$ To further enable their expansion and directed differentiation in

Received: November 19, 2017

Revised: February 18, 2018

Published: March 12, 2018 
3D for applications such as drug screening, disease modeling, and eventually regenerative medicine, inert synthetic scaffolds and gentle release methods are required for optimal culture and recovery of the cells for further downstream applications. ${ }^{21,22}$ However, to reach such end-stage applications in the biomedical area with supramolecular materials, structurally simple and biocompatible monomers with high synthetic accessibility that robustly self-assemble into polymeric architectures are necessary.

To promote supramolecular polymerization of a given monomer, a combination of noncovalent interactions such as hydrogen bonding, $\pi$-stacking, van der Waals and/or electrostatic interactions, are engineered into the monomer unit. ${ }^{23-28}$ Hydrogen bonds are often employed because of their capacity to engender directional interactions between monomers while providing a handle to tune the strength of their association by their type, number, arrangement, and microenvironment. ${ }^{29,30}$ Commonly used hydrogen bonding synthons include amides, ${ }^{31}$ thioamides, ${ }^{32}$ ureas $^{33,34}$ and thioureas. ${ }^{35}$ Despite their extensive use in the areas of bioconjugation, ${ }^{36}$ medicinal chemistry, ${ }^{37}$ catalysis, ${ }^{38}$ and anion recognition, ${ }^{39}$ squaramides have been explored to a far lesser extent in the materials domain, especially with respect to self-assembly, ${ }^{39-41}$ with few examples reported in water, ${ }^{42-44}$ and none thus far have been applied to 3D cell culture.

Squaramides are minimal ditopic hydrogen bonding units that possess two strong $\mathrm{N}-\mathrm{H}$ hydrogen bond donors and two $\mathrm{C}=\mathrm{O}$ hydrogen bond acceptors opposite one another on a conformationally rigid cyclobutenedione ring. ${ }^{45}$ Their capacity to engage in strong hydrogen bonding interactions renders them as attractive building blocks to prepare noncovalent materials. ${ }^{46}$ Previously, our group has demonstrated that these highly directional hydrogen bonding units can facilitate the formation of robust supramolecular polymers when incorporated into a bolaamphiphilic monomer benefiting from the interplay between hydrogen bonding and aromaticity in the squaramide unit. ${ }^{42}$ We became interested in applying the squaramide synthon to a C3-type monomer geometry because of the possibilities for increased control over their self-assembly properties into one-dimensional aggregates. ${ }^{47,48}$ On the basis of its commercial availability and structural simplicity, the flexible tripodal core tris(2-aminoethyl)amine (TREN) $)^{49-53}$ was selected for coupling to the rigid squaramide unit so as to explore the self-assembly scope of this strongly hydrogen bonding synthon. Thus, we report for the first time the synthesis of a library of flexible tripodal squaramide-based supramolecular polymer monomers and examine their selfassembly into supramolecular materials for applications in the 3D culture of hiPSCs and their derivatives.

\section{EXPERIMENTAL SECTION}

Materials. All chemicals and reagents for synthesis of the tripodal squaramide-based monomers were obtained from commercial suppliers and used without further purification. Deuterated dimethyl sulfoxide, methanol, and chloroform were purchased from Euriso-top. Dulbecco's modified Eagle medium (DMEM) was obtained from Gibco, Life Technologies. Eight-well Lab-Tek slides and the NucGreen Dead reagent were purchased from Thermo Fisher Scientific. Propidium Iodide (PI), calcein AM (AM = acetoxymethyl), and 3[4,5-dimethyl-2-thiazolyl]-2,5-diphenyl- $2 \mathrm{H}$-tetrazolium bromide (MTT) were purchased from Sigma-Aldrich. TeSR-E8 cell culture medium was purchased from STEMCELL Technologies, and TrypLE Select Enzyme together with RevitaCell (1:100) were from Invitrogen. TRA-1-60 (Podocalyxin) and SSEA-4-VioBlue fluorescently labeled monoclonal antibodies were from Miltenyi Biotec, and EGM-2 medium was purchased from PromoCell. Water was deionized prior to use.

Synthesis of Tripodal Squaramide-Based Monomers. Full synthetic details of tripodal squaramide and urea-based monomers 15 can be found in the Supporting Information. Purification of the tripodal squaramide-based monomers 1-4 was carried out on a Grace Reveleris X1 flash chromatography system equipped with a C18 column, and subsequently by RP-HPLC on a Vydac C18 reversedphase column with UV detection. The tripodal urea-based monomer 5 (see Supporting Information) was purified using an Agilent 1200 HPLC system equipped with a C18 column using mass detection on an Agilent Technologies Q6130. ${ }^{1} \mathrm{H}$ NMR and ${ }^{13} \mathrm{C}$ NMR spectra were recorded on a Bruker DMX-400 $(400 \mathrm{MHz})$ operating at $400 \mathrm{MHz}$ for ${ }^{1} \mathrm{H}$ NMR and $100 \mathrm{MHz}$ for ${ }^{13} \mathrm{C}$ NMR at $298 \mathrm{~K}$. LC-MS data were collected on a Finnigan Surveyor HPLC system equipped with a Gemini C18 column $(50 \times 4.60 \mathrm{~mm}$, UV detection from 200 to 600 $\mathrm{nm}$ ) and coupled to a Finnigan LCQ Advantage Max mass spectrometer with ESI. The gradient for the mobile phase was 10$90 \%$ of $\mathrm{CH}_{3} \mathrm{CN}-\mathrm{H}_{2} \mathrm{O}$ (0.1\% TFA) over $13.5 \mathrm{~min}$. Matrix-assisted laser desorption ionization-time-of-flight mass spectra (MALDI-TOF-MS) were recorded on a Bruker microflex LRF mass spectrometer in linear positive-ion mode using $\alpha$-cyano-4-hydroxycinnamic acid as a matrix on a ground steel target plate.

Oscillatory Rheology. Oscillatory rheology experiments were performed on a Discovery hybrid rheometer DHR-2 (TA Instruments) using cone-plate geometry $\left(40 \mathrm{~mm}, 1.995^{\circ}\right)$ at $(25 \pm 0.2)^{\circ} \mathrm{C}$ or $(37 \pm 0.2){ }^{\circ} \mathrm{C}$ with a Peltier-based temperature control and a solvent trap. Hydrogels $2(800 \mu \mathrm{L}, 5.6 \mathrm{mM})$ and $3(800 \mu \mathrm{L}, 3.1 \mathrm{mM})$ in deionized water or in PBS ( $\mathrm{pH}$ 7.4) were prepared by sonication for $20 \mathrm{~min}$ and left to stand overnight before being pipetted onto the lower plate of the rheometer. All time sweep measurements were performed at a frequency $(f)$ of $1.0 \mathrm{~Hz}$ with $0.05 \%$ strain. Frequency sweeps were conducted in the range of $0.01-2 \mathrm{~Hz}$ with $0.05 \%$ strain. Strain sweeps were measured in the range of $0.001-300 \%$ strain for hydrogel 2 and $0.001-100 \%$ for hydrogel 3 at a constant frequency of $1 \mathrm{~Hz}$. Prior to measuring self-recovery of the supramolecular materials, a time sweep measurement was performed first $(f=1.0 \mathrm{~Hz}, \gamma=0.05 \%)$ followed by a frequency sweep $(f=0.01$ to $2 \mathrm{~Hz}, \gamma=0.05 \%)$. Once a plateau in the storage modulus $\left(G^{\prime}\right)$ was reached, a strain of $200 \%$ for hydrogel 2 and $100 \%$ strain for hydrogel 3 was applied for $120 \mathrm{~s}$. The gel was then allowed to recover while measuring at $0.05 \%$ strain and continued with a frequency sweep (from 0.01 to $2 \mathrm{~Hz}, \gamma=0.05 \%$ ) back to the original plateau of the storage modulus. The strain was alternated in this manner for two cycles.

Cryogenic Transmission Electron Microscopy (Cryo-TEM). Cryo-TEM images of the vitrified samples were acquired with a Tecnai F20 microscope (FEI) equipped with a field emission gun operating at $200 \mathrm{keV}$ using a Gatan UltraScan charge-coupled device (CCD) camera with a defocus between -6 and $-9 \mu \mathrm{m}$. Tomographic tilt series were acquired at a magnification of $\times 29 \mathrm{k}$ using a continuous tilt scheme from $-51^{\circ}$ to $+51^{\circ}$ in $3^{\circ}$ increments, focusing to $-8 \mu \mathrm{m}$ every third image using a low-dose routine. The tomogram was processed using IMOD, ${ }^{54}$ aligned using patch tracking methods and reconstructed using 5 iterations of simultaneous iterative reconstruction technique (SIRT). For visualization, the tomogram was lowpass filtered to $5 \mathrm{~nm}$ and binned $2 \times$ for a final pixel size of $1.6 \mathrm{~nm}$. Disconnected particles larger than 200 voxels were removed using UCSF Chimera. ${ }^{55}$ Cryo-TEM samples were prepared by applying $3 \mu \mathrm{L}$ of hydrogels $2(5.6 \mathrm{mM}), 3(3.1 \mathrm{mM})$ or solutions of 2 or $3(1.5 \times$ $10^{-5} \mathrm{M}$ ) without further dilution to a freshly glow-discharged 300 mesh copper grid with a lacey-carbon support film (Supplier-Electron Microscopy Sciences). Excess liquid was blotted away for 2 s (95\% humidity, $21{ }^{\circ} \mathrm{C}$, Whatman No. 4 filter paper) and plunge-frozen in liquid ethane at $-183{ }^{\circ} \mathrm{C}$ using a Leica EM GP (Leica Microsystems) before imaging.

Small-Angle X-ray Scattering (SAXS). SAXS measurements of monomer $3(2 \mathrm{mg} / \mathrm{mL})$ in deionized water were prepared by sonication of the sample for $20 \mathrm{~min}$ in an ultrasonic bath and left to stand overnight at room temperature before pipetting into $2 \mathrm{~mm}$ 
quartz capillaries (Hilgenberg $\mathrm{GmbH}$ ). These samples were measured on a SAXSLAB GANESHA $300 \mathrm{XL}$ SAXS system equipped with a GeniX 3D $\mathrm{Cu}$ ultralow divergence microfocus sealed tube source producing X-rays with a wavelength of $\lambda=1.54 \AA$ at a flux of $1 \times 10^{8}$ $\mathrm{ph} / \mathrm{s}$ and a Pilatus $300 \mathrm{~K}$ silicon pixel detector with $487 \times 619$ pixels of $172 \times 172 \mu \mathrm{m}$ in size placed at two sample-to-detector distances of 713 and $1513 \mathrm{~mm}$, respectively, to access a $q$-range of $0.009 \leq q \leq$ $0.456 \AA^{-1}$, where $q=4 \pi / \lambda(\sin \theta / 2)$. The calibration of the beam center and $q$-range was achieved by using silver behenate. The SAXS patterns were brought to an absolute intensity scale using the calibrated detector response function, known sample-to-detector distance, measured incident, and transmitted beam intensities and were azimuthally averaged to obtain one-dimensional SAXS profiles. The scattering curves of the self-assembled fibers were obtained by subtraction of the scattering contribution of the solvent and quartz cell using SAXS utilities in the software package (http://www.sztucki.de/ SAXSutilities/). The resulting SAXS profiles were analyzed using the software package SASview (http://www.sasview.org/).

UV-Vis Spectroscopy. UV-Vis spectra were recorded on a Cary 300 spectrophotometer (Agilent) using a quartz cuvette with a path length of $1 \mathrm{~cm}$. Stock solutions of 2 and 3 in deionized water $(1.5$ $\mathrm{mM}$ ) were prepared separately with 20 min sonication in an ultrasonic bath and were subsequently diluted to their measured concentrations. The individual samples were left to stand overnight at room temperature prior to measurements.

Fluorescence Spectroscopy. Fluorescence spectra were acquired on a TECAN Infinite M1000 PRO fluorescent plate reader. A stock solution of Nile Red dye in methanol $(0.005 \mathrm{mg} / \mathrm{mL})$ was prepared. Aliquots $(12 \mu \mathrm{L})$ from the Nile Red stock solution were pipetted into the individual wells of a 96-well plate. Subsequently, the methanol was removed by placing the 96-well plate into a vacuum oven for $2 \mathrm{~h}$ at room temperature. Stock solutions of $\mathbf{1 - 3}$ were prepared in deionized water $(1.5 \mathrm{mM})$ with sonication for $20 \mathrm{~min}$ in an ultrasonic bath. Aliquots $(10 \mu \mathrm{L})$ were taken from these stock solutions and diluted in deionized water $(990 \mu \mathrm{L})$ to obtain the desired concentration $(1.5 \times$ $10^{-5} \mathrm{M}$ ). Subsequently, the diluted solutions of $1-3$ were pipetted into the 96-well plate containing the Nile Red dye and left to stand overnight prior to measurements. As a negative control, the Nile Red dye was also measured in water $(200 \mu \mathrm{L})$ within the microplate.

Fourier Transform Infrared (FTIR) Spectroscopy. IR spectra were recorded on a PerkinElmer Spectrum Two UATR FT-IR spectrometer with a resolution of $4 \mathrm{~cm}^{-1}$. Samples of 1-3 were first prepared in deionized water $(400 \mu \mathrm{L}, 3.1 \mathrm{mM})$ in an ultrasonic bath for $20 \mathrm{~min}$ and left to stand overnight. The samples were then lyophilized prior to solid FTIR measurements.

Cell Culture. A NIH 3T3 cell line was cultured and maintained in DMEM medium with $10 \%$ FBS. A hiPSC line $\left(\right.$ SFLB6) ${ }^{56}$ was maintained on human recombinant vitronectin-coated plates in TeSRE8 cell culture medium (STEMCELL Technologies). hiPSC-derived endothelial cells (ECs) were cultured on gelatin-coated plates in ECSFM (Invitrogen) additionally supplemented with $1 \%$ platelet-poor serum, $30 \mathrm{ng} / \mathrm{mL}$ of VEGF, and $20 \mathrm{ng} / \mathrm{mL}$ of bFGF as previously described. $^{57}$ For NIH 3T3 cells, 100 units/mL of penicillin and 100 $\mu \mathrm{g} / \mathrm{mL}$ of streptomycin were added to the culture media, whereas hiPSCs and hiPSC-derived endothelial cells were cultured in penicillin/streptomycin-free medium. All cells were cultured in an incubator at $37{ }^{\circ} \mathrm{C}$ with a $5 \% \mathrm{CO}_{2}$ atmosphere.

MTT Assays. NIH 3T3 cells were seeded at a density of 1500 cells/ well in a 96-well plate and allowed to adhere overnight. Aliquots of 13 were pipetted into the wells to provide final concentrations of 1,10 , 50,100 , and $200 \mu \mathrm{M}$ in PBS or deionized water and incubated with the cells for 24 and $72 \mathrm{~h}$. Measurements were performed for each condition in triplicate. A $10 \mu \mathrm{L}$ aliquot of a 3-[4,5-dimethyl-2thiazolyl]-2,5-diphenyl-2H-tetrazolium bromide (MTT) stock solution ( $5 \mathrm{mg} / \mathrm{mL}$ in PBS) was added to each well. After incubation for $2-3 \mathrm{~h}$ with MTT, the medium was aspirated, and $200 \mu \mathrm{L}$ of DMSO was added to dissolve the formazan crystals produced. Cell viability was calculated from the absorbance measured at $570 \mathrm{~nm}$ on a fluorescence microplate reader (TECAN).
3D Cell Encapsulation Studies. NIH $3 \mathrm{~T} 3$ cells were harvested and resuspended in PBS at a concentration of $5 \times 10^{6}$ cells $/ \mathrm{mL}$. The cell suspension $(20 \mu \mathrm{L})$ was mixed with premade hydrogels of 2 (180 $\mu \mathrm{L}$ PBS, $6.2 \mathrm{mM})$ or $3(180 \mu \mathrm{L}$ PBS, $3.4 \mathrm{mM})$, resulting in final concentrations of $2(5.6 \mathrm{mM})$ and $3(3.1 \mathrm{mM})$ after gently pipetting the gels up and down $(\sim 10$ times). The cell-laden hydrogels $(200 \mu \mathrm{L})$ were transferred into an 8 -well chamber slide by pipetting. After waiting $15 \mathrm{~min}$ at room temperature, cell culture media $(100 \mu \mathrm{L})$ was then layered on top of the hydrogels before placing them in an incubator at $37^{\circ} \mathrm{C}$. LIVE/DEAD (calcein AM/propidium iodide (PI)) staining of the hydrogels was subsequently performed at specific time points. Stock solutions of calcein AM $(2.5 \mathrm{mM}$ in $\mathrm{DMSO})$ and PI (1.5 mM in PBS) were prepared and stored at $-20{ }^{\circ} \mathrm{C}$; these stock solutions were diluted with PBS to obtain a staining solution containing both dyes at final concentrations of 2 and $1.5 \mu \mathrm{M}$, respectively. The medium on top of the hydrogel was removed by pipetting, and the hydrogel was first washed once with PBS $(100 \mu \mathrm{L})$ before incubation with the staining solution $(100 \mu \mathrm{L})$ for $30 \mathrm{~min}$ at room temperature. Afterward, the excess staining solution was removed, and the hydrogel was washed twice gently with PBS (100 $\mu \mathrm{L})$. Additional PBS $(100 \mu \mathrm{L})$ was added, and the hydrogelencapsulated cells in 3D were imaged on a Zeiss LSM 710 confocal laser scanning microscope equipped with a Zeiss $5 \times$ objective. Fluorescent Z-stack images ( 35 images/per sample) through the gel were acquired at a resolution of $512 \times 512$ pixels using an excitation wavelength of $488 \mathrm{~nm}$ and an emission filter of 519-582 nm for calcein AM, and an excitation wavelength of $532 \mathrm{~nm}$ and an emission filter of $615-695 \mathrm{~nm}$ for PI. Cell viability was determined by counting the calcein AM-stained green cells (viable) and PI-stained red cells (dead) in ImageJ. Z-stack images of 3D cell-laden hydrogels 2 and 3 were taken after 2 and $48 \mathrm{~h}$, respectively. For each hydrogel sample at each time point, five $Z$-stack images were counted totaling more than 400 cells.

hiPSC-derived ECs and hiPSCs and were dissociated to single cells using $1 \times$ TrypLE Select, and the cells were encapsulated in a hydrogel of 3 in 3D using a similar procedure as described earlier for the NIH $3 \mathrm{~T} 3$ cells. Cell suspensions of hiPSC-derived ECs $\left(5 \times 10^{6}\right.$ and $2 \times$ $10^{7}$ cells $\left./ \mathrm{mL}\right)$, and hiPSCs $\left(2 \times 10^{7}\right.$ cells $\left./ \mathrm{mL}\right)$ were used for $3 \mathrm{D}$ cell seeding within the hydrogels. Aliquots of the various cell suspensions $(10 \mu \mathrm{L})$ were mixed with premade hydrogels of 3 (90 $\mu \mathrm{L}$ PBS, 3.4 $\mathrm{mM}$ ) by gentle pipetting to provide a final gel concentration of 3 (3.1 $\mathrm{mM}$ ). After being left to stand for $15 \mathrm{~min}$ at room temperature, 200 $\mu \mathrm{L}$ of cell culture medium was layered on top of the $3 \mathrm{D}$ cell-laden hydrogels. For hiPSCs, TeSR-E8 medium was additionally supplemented with RevitaCell (1:100) when layered on top of the hydrogels, and EGM-2 medium was used for hiPSC-ECs. For the wells containing hiPSCs, the culture medium was refreshed every $\sim 12 \mathrm{~h}$ with TeSR-E8. Time-lapse imaging was performed using the EVOS FL AUTO2 system. $Z$-stack images were acquired with a $10 \times$ objective every 15 min for a period from 24 to $72 \mathrm{~h}$. Cell viability was determined using NucGreen Dead reagent (ThermoFisher) after $24 \mathrm{~h}$ for both hiPSC and hiPSC-ECs and $72 \mathrm{~h}$ for hiPSCs.

FACS Analysis. Fluorescence-activated cell sorting (FACS) was performed to quantify the undifferentiated state of hiPSCs. TRA-1-60PE and SSEA-4-VioBlue fluorescently labeled antibodies were incubated with the cells at a 1:20 dilution at room temperature and recorded on a MACSQuant VYB flow cytometer with a $561 \mathrm{~nm}$ laser for excitation and a 586/15 nm Y1 filter (PE) and $405 \mathrm{~nm}$ laser for excitation and a 450/50 nm V1 filter (VioBlue). After $24 \mathrm{~h}$ incubation, hiPSCs were released from the hydrogel $(100 \mu \mathrm{L})$ using gentle mechanical dissociation by pipetting $(\sim 15-20$ times $)$ from the wells and diluted into $1 \times$ PBS $(\sim 50 \times$ volume). The isolated cell suspension from the gel was washed $3 \times$ times with $1 \times$ PBS $(3 \mathrm{~mL})$ followed by centrifugation for $3 \mathrm{~min}$ at $300 \mathrm{~g}$. Cells were dissociated to a single-cell suspension using $1 \times$ TrypLE Select, and FACS staining was performed as previously described. ${ }^{57}$ hiPSCs cultured on vitronectin-coated plates using standard procedures as described above were used as a positive control in all FACS experiments. 

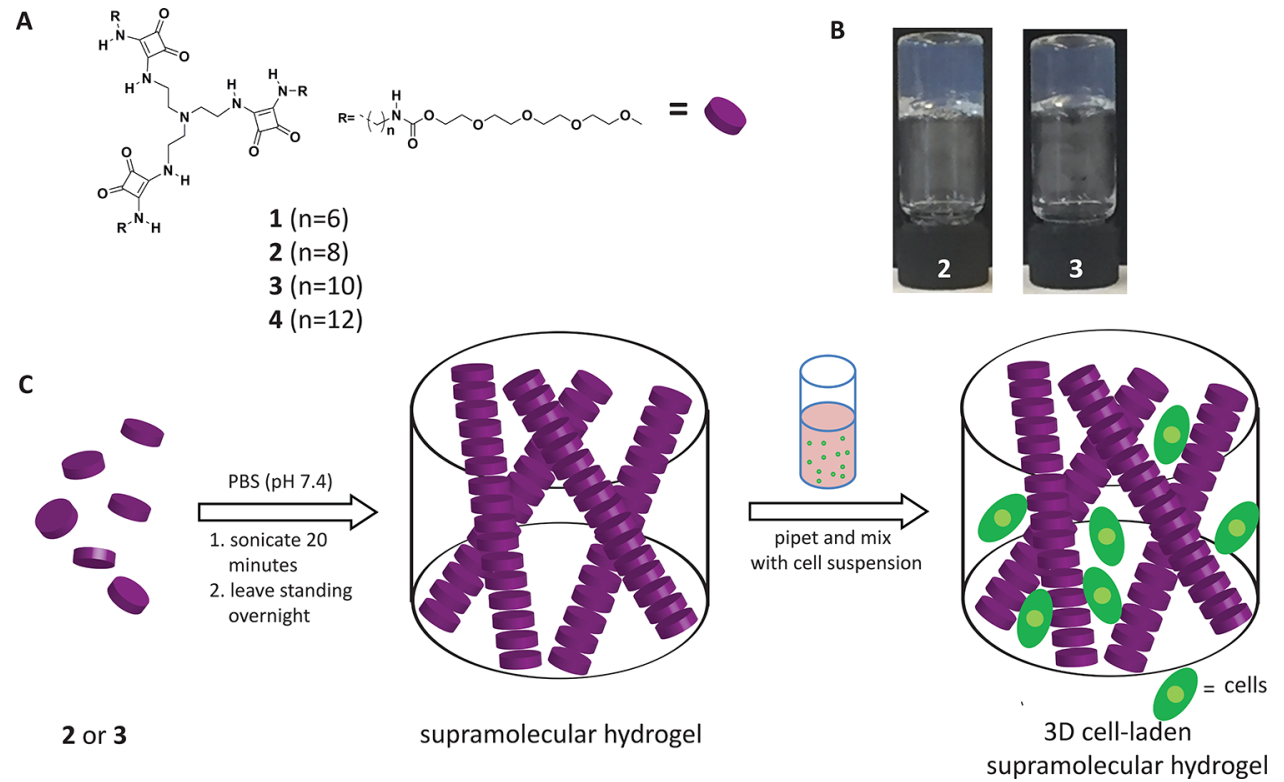

Figure 1. (A) Tripodal squaramide-based monomers 1-4 with varied alkyl chain lengths $(n=6,8,10,12)$. (B) Gel inversion test of squaramidebased materials above the CGC of $2(5.6 \mathrm{mM})$ and $3(3.1 \mathrm{mM})$ in deionized water. (C) Supramolecular hydrogel preparation and 3D cell seeding strategy.
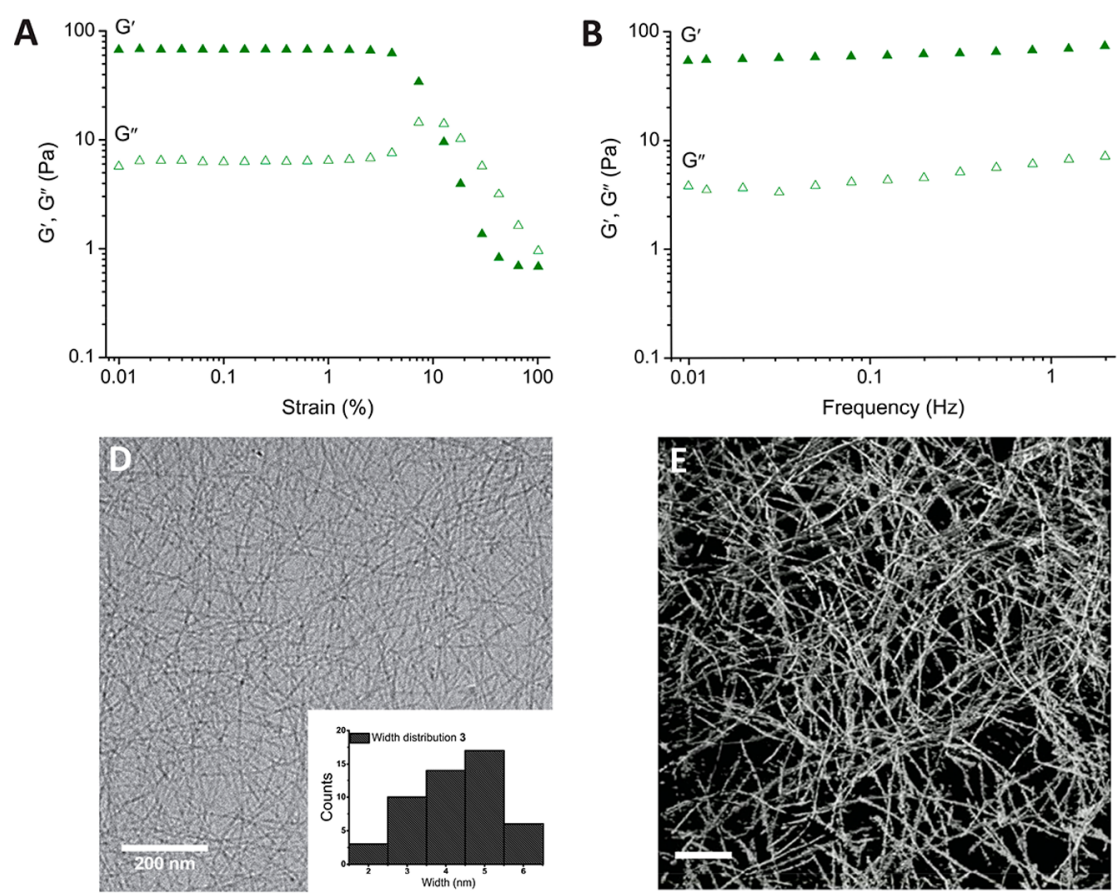

Figure 2. Oscillatory rheology measurements of hydrogel $3(3.1 \mathrm{mM})$ in PBS (pH 7.4) at $37^{\circ} \mathrm{C}$ : (A) Amplitude sweep $(f=1 \mathrm{~Hz})$. (B) Frequency sweep $(\gamma=0.05 \%)$. (C) Step strain measurements $(f=1 \mathrm{~Hz})$; the absence of data before the application of high strain is due to the acquisition of a frequency sweep $(f=0.01$ to $2 \mathrm{~Hz}, \gamma=0.05 \%)$. (D) Cryo-TEM image of hydrogel 3 (3.1 mM). Insert: Histograms of fiber width distribution for a sample size of $N=50$. (E) Cryo-electron tomography image image of a hydrogel of 3 (3.1 mM). Scale bar: $200 \mathrm{~nm}$. (F) Small-angle X-ray scattering profiles of fibers 3 collected at a concentration of $2 \mathrm{mg} / \mathrm{mL}$. Black dots represent experimental data; red line represents fit with a form factor for flexible cylinders.

\section{RESULTS AND DISCUSSION}

Tripodal Squaramide-Based Amphiphile Design and Synthesis. A library of tripodal squaramide-based monomers was synthesized to probe their potential to gelate water. The central TREN core with three squaramide units is connected to alkyl chains with a variable number of methylene units $(n=6$, 8 , 10, or 12) to form the hydrophobic portion of the amphiphile. The hydrophilic domain is composed of tetraethylene glycol monomethyl ether oligomers that are coupled to the hydrophobic domain through a carbamate moiety (1-4, Figure 1A). Compounds 1-4 were synthesized by reacting tetraethylene glycol monomethyl ether with 1,1-carbonyldiimidazole followed by reaction with an excess of the carboxybenzyl $(\mathrm{Cbz})$-protected linear $1, n$-alkyldiamine $(n=6,8,10,12)$ with yields ranging from 48 to $71 \%$. The $\mathrm{Cbz}$ protecting group was 
deprotected by catalytic hydrogenation to reveal an amine moiety, which was further reacted with dibutyl squarate and DIPEA to provide yields of $52-73 \%$. In a final step, the squaramide amphiphile was reacted with TREN to obtain the final tripodal squaramide-based monomers with yields in the range of $42-54 \%$ (see Supporting Information). To better understand the role of the squaramide moiety in the selfassembly of the materials (vide infra), molecule $5(n=10)$ bearing urea moieties was synthesized (see Supporting Information) with a final yield of $56 \%$.

Supramolecular Material Self-Assembly. The sol-to-gel transition of the squaramide-based monomers 1-4 in aqueous solution were tested by the gel inversion method. Monomers 1-4 were all poorly soluble in deionized water, even with heating. Their sonication at room temperature in an ultrasonic bath resulted in their initial dissolution with transparent hydrogels being formed for $\mathbf{2}$ and $\mathbf{3}$ from the library (Figure 1B). Monomer 3 formed gels immediately after sonication when above its critical gelation concentration (CGC) of 1.3$1.9 \mathrm{mM}$; however, 2 required a significantly higher concentration of the monomer $(4.0-4.6 \mathrm{mM})$ and a longer period of time for gelation to occur (Figures S1 and S2). Conversely, 1 formed clear solutions, eventually precipitating at concentrations above $4.2 \mathrm{mM}$, whereas 4 with the longest alkyl chain $(n=12)$ was insoluble in water even after a longer sonication period of $1 \mathrm{~h}$. When the squaramide moieties of 3 were replaced with ureas (5), clear solutions instead of hydrogels were obtained at a concentration of $3.1 \mathrm{mM}$. Further increasing the concentration of $5(5 \mathrm{mM})$ resulted in its precipitation, pointing out the importance of the squaramide motif for gelation of the tripodal monomer in water.

The mechanical properties of hydrogels 2 and 3 were measured by oscillatory rheology in deionized water at $25^{\circ} \mathrm{C}$ and also in phosphate buffered saline (PBS) at $37^{\circ} \mathrm{C}$ (Figure 2, Figures S3 and S4). The linear viscoelastic regime (LVE) was first determined by an amplitude experiment. For a hydrogel composed of 3 in deionized water at $25^{\circ} \mathrm{C}$ or in PBS at $37^{\circ} \mathrm{C}$, the storage $\left(G^{\prime}\right)$ and loss $\left(G^{\prime \prime}\right)$ moduli remained constant until $3 \%$ strain at a fixed frequency of $1 \mathrm{~Hz}$, whereas for a hydrogel composed of 2 , both moduli remained constant until the application of $10 \%$ strain. In frequency sweep experiments of hydrogels 2 and 3, $G^{\prime}$ was found to be greater than $G^{\prime \prime}$ by nearly an order of magnitude and frequency independent over the measured range from 0.01 to $2 \mathrm{~Hz}$, synonymous with the formation of a viscoelastic material. The hydrogels at $37^{\circ} \mathrm{C}$ in PBS $\left(G^{\prime}=37\right.$ Pa for $2 ; G^{\prime}=64$ Pa for 3) showed similar storage moduli to those at $25{ }^{\circ} \mathrm{C}$ in deionized water $\left(G^{\prime}=46\right.$ Pa for 2; $G^{\prime}=67 \mathrm{~Pa}$ for 3). Moreover, step-strain experiments were performed to examine the potential of supramolecular hydrogels 2 and 3 to self-recover after the application of large strain. When a large amplitude strain was applied (200\% for hydrogel 2 and $100 \%$ for hydrogel 3 at a frequency of $1 \mathrm{~Hz}$ in deionized water at $25{ }^{\circ} \mathrm{C}$ or in PBS at $37^{\circ} \mathrm{C}$ ) for $120 \mathrm{~s}$, the $G^{\prime}$ value of both hydrogels 2 and 3 decreased and showed an inversion of their moduli $\left(G^{\prime \prime}>G^{\prime}\right)$. However, when the large amplitude strain was removed, both hydrogels 2 and 3 quickly recovered back to the gel state $\left(G^{\prime}>G^{\prime \prime}\right)$. The recovery of the hydrogel materials after the application of a cyclic strain was demonstrated over 2 cycles.

To understand the origin of the rheological properties of 2 and 3, cryogenic transmission electron (cryo-TEM) microscopy was performed. Imaging of the network at the nanoscale by cryo-TEM revealed fibers greater than a micrometer in length with a width of $(5.4 \pm 1.0) \mathrm{nm}$ for a hydrogel composed of 2 (5.6 mM, Figure S5) and (4.2 \pm 1.1$) \mathrm{nm}$ for 3 (3.1 mM, Figure 2D). Cryo-electron tomography was further executed on hydrogel 3, providing a view into the organization of the 3D fibrillar network (see tomography image and movie in the Supporting Information). Presumably, the gel properties arise from the entanglements of the self-assembled fibers of the squaramide-based monomers (Figure 2E). This observation is in contrast to cryo-TEM images taken for solutions of $\mathbf{5}$ after sonication that show domains of fiber alignment rather than entanglement (Figure S6). ${ }^{58}$ The cryo-TEM images of 3 were further supported by small-angle X-ray scattering experiments (SAXS) in the solution phase, where scattering profiles showed the formation of high-aspect-ratio one-dimensional aggregates. The data were best described with a form factor for flexible cylinders, which yielded a cross-sectional radius $\left(r_{\mathrm{cs}}\right)$ of $2.6 \mathrm{~nm}$, a cross-sectional mass per unit length $\left(M_{\mathrm{L}}\right)$ of $2.42 \times 10^{-21} \mathrm{~g}$ $\mathrm{nm}^{-1}$, and a Kuhn length of $6.6 \mathrm{~nm}$ (Figure 2F). By applying eqs 1 and 2 (Supporting Information) and by estimation of the $I_{\text {cs }}$ (Figure S9), 1 monomer $/ \mathrm{nm}$ was determined along the fibrillar axes. These results indicate that transitioning from a bola-amphiphilic ${ }^{42}$ to a pseudo-C3 symmetric monomer geometry reduces lateral monomer aggregation and increases fiber length and flexibility.

Spectroscopic methods were pursued to gain insight into the effect of the hydrophobic-hydrophilic balance of monomers 1-3 on squaramide self assembly. Monomers 2 and 3 (1.5 $\times$ $10^{-5} \mathrm{M}$ ) showed two distinct absorption bands at 255 and 329 $\mathrm{nm}$ consistent with simultaneous red- and blue-shifting of the $\mathrm{HOMO}-\mathrm{LUMO}$ and $\mathrm{HOMO}-\mathrm{LUMO}+1$ transitions, respectively, upon aggregation (Figure $3 \mathrm{~A}) .^{42}$ Their self-assembly is further supported by cryo-TEM imaging performed on dilute solutions 2 and 3 in water $\left(1.5 \times 10^{-5} \mathrm{M}\right.$, Figure S7), which showed the presence of long fibers. Concentration-dependent measurements of $\mathbf{2}$ and $\mathbf{3}$ displayed retention of these bands at concentrations as low as $3.75 \times 10^{-6} \mathrm{M}$ for 2 and $1.5 \times 10^{-6} \mathrm{M}$ for 3 (Figure S10). Conversely, 1 with the shortest alkyl spacer $(n=6)$ displayed only a single band. The spectrum obtained for $\mathbf{1}$ in water bears resemblance to the spectra collected for $\mathbf{2}$ and 3 in hexafluoroisopropanol (HFIP), a low dielectric solvent known to disrupt hydrogen bonds (Figure S11), and is thus suggestive of a lesser degree of monomer aggregation. Fluorescence measurements using Nile Red as a probe of the hydrophobic environment support the results of the UV-Vis measurements (Figure 3B). Compound $\mathbf{1}$ does not affect the fluorescence intensity and maximum wavelength of the Nile Red dye in water, whereas compound 3 showed the greatest increase in fluorescence intensity and blue-shifting $(622 \mathrm{~nm})$ of the Nile Red peak $(659 \mathrm{~nm})$ relative to $2(633 \mathrm{~nm})$. Fourier transform infrared (FTIR) spectroscopy on lyophilized samples from gel inversion experiments supported the presence of hydrogen bonding and hydrophobic interactions between the tripodal squaramide-based supramolecular monomers. ${ }^{42}$ Samples 1-3 displayed two distinct frequencies for the $\mathrm{N}-\mathrm{H}$ stretch of the carbamate $\left(3317-3315 \mathrm{~cm}^{-1}\right)$ and squaramide units $\left(3167-3164 \mathrm{~cm}^{-1}\right)$. Additionally, the antisymmetric and symmetric $\mathrm{C}-\mathrm{H}$ stretches were shifted to lower wavenumbers with increasing length of the alkyl chains (from $n=6$ to 10) from 2931 and $2861 \mathrm{~cm}^{-1}$ to 2918 and $2850 \mathrm{~cm}^{-1}$, respectively; these are indicative of their close packing within the supramolecular polymer (Figure 3C, inset). ${ }^{59,60}$ All samples showed a small broad band at $1799 \mathrm{~cm}^{-1}$ associated with ring breathing of the squaramide unit and one or two $\mathrm{C}=\mathrm{O}$ 
A
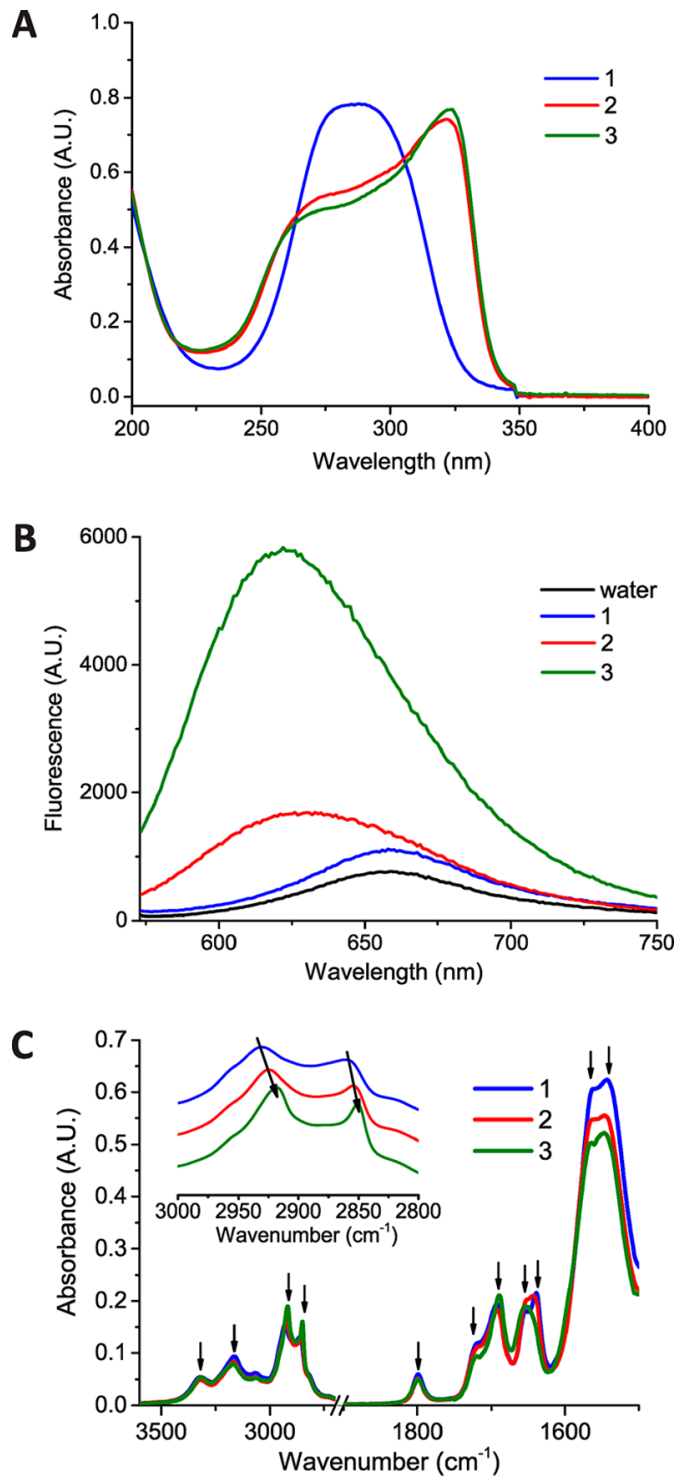

Figure 3. (A) UV-Vis spectra of $\mathbf{1 - 3}$ in deionized water $\left(1.5 \times 10^{-5}\right.$ $\mathrm{M})$. (B) Fluorescence spectra of solutions of Nile Red $\left(1.0 \times 10^{-6} \mathrm{M}\right.$, ex. $550 \mathrm{~nm}$, em. $560-750 \mathrm{~nm}$ ) in deionized water and in the presence of 1-3 $\left(1.5 \times 10^{-5} \mathrm{M}\right)$. (C) FTIR spectra of $1-3$ in the solid state (samples lyophilized from deionized water $(3.1 \mathrm{mM})$, arrows highlight peaks considered).

stretching modes of the carbamates and squaramides in the amide I region (Figure 3C and Table S2). The variable number of bands in the amide I region suggests that more than one packing mode of the various monomers exists in the selfassembled state.

Hence, the squaramide unit can be employed to robustly selfassemble flexible amphiphilic monomers through a combination of hydrophobic and hydrogen bonding interactions into long fibrillar aggregates and eventually gel phase materials in water. Their mechanical "softness" is attractive for the culture of hiPSCs because of their similar Young's modulus $(E \sim 200 \mathrm{~Pa}$ using the relationship $E \sim 3 G$ for a hydrogel material, where $G$ is the elastic shear modulus ${ }^{61}$ ) in comparison to embryonic tissues (ranging from tens to several hundreds of Pascals ${ }^{62-64}$ ). Moreover, the self-recovering character of the squaramidebased supramolecular materials opens the door for the gentle encapsulation and release of hiPSCs.
Cell Viability and 3D Cell Culture Studies. To apply these tripodal squaramide-based supramolecular polymers in the biomedical area, as either nanoparticles or hydrogel scaffolds, we first evaluated their cytocompatibility with NIH 3T3 cells. The cytotoxicity of monomers 1-3 with increasing concentration $(1-200 \mu \mathrm{M})$ in both water and PBS were evaluated by an MTT cytotoxicity assay (Figure S12). The cell viability was $\sim 95 \%$ for monomers $\mathbf{1 - 3}$ as the concentration was increased from 1 to $200 \mu \mathrm{M}$ and applied for 24 and $72 \mathrm{~h}$, similar to the control sample. These results indicate that supramolecular polymers constructed from monomers 1-3 in the solution phase are cytocompatible in the range of tested concentrations during the culture period.

As hydrogels, 2 and 3 were further examined for their capacity to encapsulate cells in $3 \mathrm{D}$ using their self-recovery character (cell seeding scheme in Figure 1C and full experimental details in Experimental Section). For both hydrogels $2(5.6 \mathrm{mM})$ and $3(3.1 \mathrm{mM}), 99$ and $98 \%$ of the cells, respectively, were well-dispersed and viable $2 \mathrm{~h}$ after the seeding process as calculated by counting viable cells in fluorescent $Z$-stack images collected by confocal microscopy (Figures S13 and S14). Moreover, after $48 \mathrm{~h}$ of seeding, $74 \%$ of cells seeded in 3D in hydrogel 2 and 77\% of cells in hydrogel 3 remained viable, as evidenced by the numerous Calcein AM positive cells and very few propidium iodide stained cells.

We further examined whether these tripodal squaramidebased materials were suitable for the 3D culture of hiPSC and hiPSC-derived endothelial cells (hiPSC-ECs). First, hiPSC-ECs were encapsulated in hydrogel 3 (with a final concentration of $3.1 \mathrm{mM}$ ) using the same technique as for the NIH 3T3 cells. The hiPSC-ECs were well-dispersed throughout the gel, and the majority remained viable after $24 \mathrm{~h}$ as observed by the virtual absence of NucGreen Dead positive cells (Figure S15). Despite being viable, no cell proliferation or cell attachment/ spreading of the hiPSC-ECs was observed in the hydrogel, which could be expected based on the lack of adherent cues (e.g., RGD) within the supramolecular matrix. Interestingly, the encapsulation of undifferentiated hiPSCs as single cells in supramolecular hydrogel 3 resulted in the formation of compact spheroids of increasing diameter after $24 \mathrm{~h}$ when seeded in 3D. Their formation was followed by time-lapse microscopy over a period of $72 \mathrm{~h}$ (see videos showing aggregate formation in the Supporting Information). Importantly, the hiPSC spheroids remained viable as observed by their morphology and the largely absent staining of dead cells with the NucGreen Dead reagent after 24 and $72 \mathrm{~h}$ (Figure 4A, B). The evolution of the hiPSC spheroid diameter after encapsulation of single hiPSCs in hydrogel $3(3.1 \mathrm{mM})$ over time $(24,48$, and $72 \mathrm{~h}$ culture) was observed to trend to larger sizes with longer culture periods (after $72 \mathrm{~h}$, spheroid diameters ranged from 26 to $143 \mu \mathrm{m}$ from single cells on day 0) and indicates that the supramolecular hydrogels do not interfere with the cell-cell contacts typically formed by these undifferentiated cells (representative images of hiPSC spheroids in hydrogel are shown in Figure 4C and Figure S16).

A major difficulty in the culture of hiPSCs is developing a facile way to release them when encapsulated in $3 \mathrm{D}$ for downstream analysis or passage because enzymatic methods may not be effective. ${ }^{65}$ This challenge has prompted the development of materials that enable cell release from a 3D environment in response to a temperature change or UV light. $^{66,67}$ Therefore, we examined the potential to gently release the hiPSCs from the squaramide-based supramolecular 

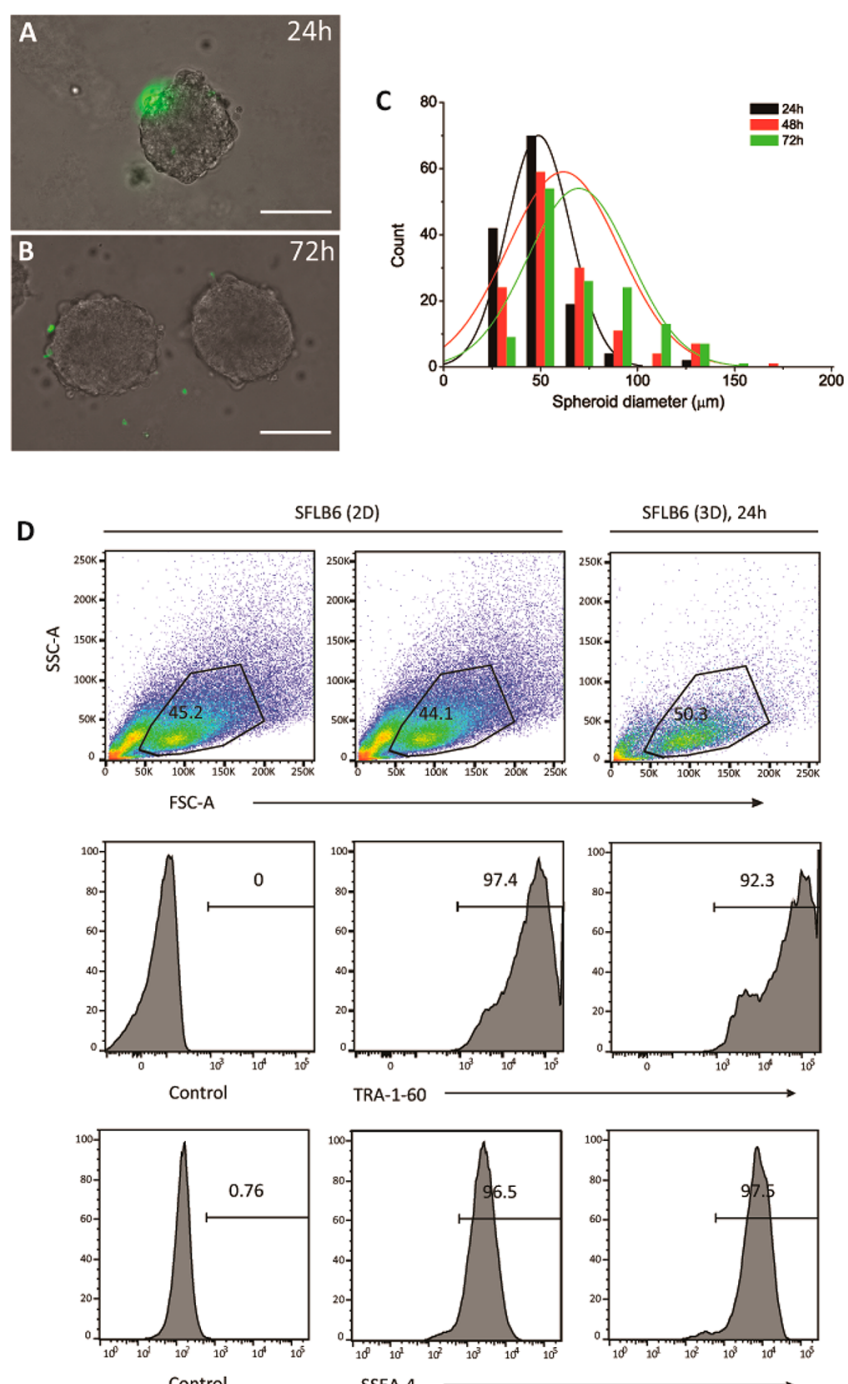

Figure 4. 3D cell culture of hiPSCs in hydrogel $3(3.1 \mathrm{mM})$ : Representative images at $\sim 24$ (A) and $\sim 72 \mathrm{~h}$ (B). Dead cells were detected using the NucGreen Dead reagent. Scale bar: $100 \mu \mathrm{m}$. (C) Distribution of spheroid diameters in a hydrogel of $3(3.1 \mathrm{mM})$ after 24,48 , and $72 \mathrm{~h} ; \sim 135$ spheroids per day were measured. (D) FACS analysis of single cells of hiPSCs cultured under standard conditions on a vitronectin surface in 2D (left control, middle with TRA-1-60 and SSEA-4 antibodies) or after retrieval from hydrogel $3(3.1 \mathrm{mM})$ after $24 \mathrm{~h}$ of culture (right with TRA-1-60 and SSEA-4 antibodies). Upper panels: side scatter (SSC-A) and forward scatter (FSC-A) showing live cell population (black circles are the gated live cells); expression levels of TRA-1-60 (middle panels) and SSEA-4 (lower panels) pluripotent stem cell markers of the gated live cells.

hydrogel materials by their simple mechanical disruption by pipetting and dilution into a $\sim 50 \times$ greater volume of PBS for analysis of pluripotent markers by fluorescence-activated cell sorting (FACS). More specifically, cell surface expression of TRA-1-60 and SSEA-4, pluripotent stem cell markers associated with the undifferentiated state, were analyzed after their dissociation into single cells and compared against hiPSCs cultured in standard maintenance conditions (i.e., vitronectincoated plates in TeSR-E8 medium), as shown comparing histograms of fluorescence intensity of the above-mentioned markers in the gated live cell population (Figure 4D). The values of mean fluorescence intensity (MFI) for the TRA-1-60 and SSEA-4 markers for hiPSCs cultured on a $2 \mathrm{D}$ surface and the hydrogels in $3 \mathrm{D}$ were positive during the culture period, with greater values measured for the hydrogels in 3D (Figure S17). Moreover, the percentage of live hiPSCs cells, as determined by side scatter (SSC-A) and forward scatter (FSC-A) events, were comparable between the $2 \mathrm{D}$ and $3 \mathrm{D}$ cultures.

Overall, the squaramide-based supramolecular hydrogels proved to be cytocompatible toward any of the cell types tested, including sensitive cells such as hiPSCs and their derivatives. The supramolecular polymer materials permitted spheroid formation from single cells and the hiPSCs retained their pluripotent state during the culture period and upon release. However, to better understand the full potential of these squaramide-based supramolecular materials for future applications such as expansion or directed differentiation, examination of longer culture periods within the materials alongside the incorporation of bioactive cues will be necessary.

\section{CONCLUSIONS}

A novel family of minimalistic tripodal squaramide-based monomers containing a flexible TREN core with varied hydrophobic $(n=6,8,10,12)$ and hydrophilic domains were successfully synthesized and characterized. With increasing concentration, namely for monomers with alkyl chain lengths of 8 and 10 carbons, self-recovering hydrogels were formed even under physiological conditions at $37{ }^{\circ} \mathrm{C}$. Additionally, cryoTEM and SAXS measurements of these hydrogels showed the formation of a network composed of entangled fibrils that were a few nanometers in width and micrometers in length. Spectroscopic measurements provided insight into the selfassembly properties of the squaramide-based supramolecular polymers at the molecular scale, indicating that hydrogen bonding and hydrophobic interactions facilitate their selfassembly. For 3D cell culture, a cytocompatible response was observed for a range of cell types, including several considered sensitive such as hiPSCs and their differentiated derivatives. Moreover, the hiPSCs produced spheroids from single cells within the supramolecular hydrogels, suggesting that these materials do not interfere with their formation through cellcell contact. Finally, the hiPSCs retain their pluripotent stem cell phenotype upon gentle isolation of the spheroids by simple dilution from the squaramide-based supramolecular material and further dissociation into single cells for FACS analysis. The simplicity of the seeding and release approach in 3D combined with the cytocompatibility of these squaramide-based materials opens the door to further explore their use for applications in 3D cell culture and delivery, namely with hiPSCs and cells that are derived from them.

\section{ASSOCIATED CONTENT}

\section{Supporting Information}

The Supporting Information is available free of charge on the ACS Publications website at DOI: 10.1021/acs.biomac.7b01614.

Full synthetic details of the tripodal squaramide-based monomers; additional data on hydrogel characterization (gel inversion, rheology results, cryo-TEM, SAXS, assignment of infrared spectra); MTT assays; confocal microscopy images of NIH 3T3 cells encapsulated in hydrogels in 3D; images of 3D cell culture of hiPSCderived ECs and hiPSCs; mean fluorescence intensity of the positive hiPSC cell populations (PDF) 
Cryo-electron tomography image of hydrogel 3 (AVI) Time-lapse microscopy video of hiPSC culture in hydrogel 3 0-24h (AVI)

Time-lapse microscopy video of hiPSC culture in hydrogel 3 24-48h (AVI)

Time-lapse microscopy video of hiPSC culture in hydrogel 3 48-60h (AVI)

\section{AUTHOR INFORMATION}

\section{Corresponding Author}

*E-mail: r.e.kieltyka@chem.leidenuniv.nl.

ORCID

Ilja K. Voets: 0000-0003-3543-4821

Roxanne E. Kieltyka: 0000-0001-9152-1810

Notes

The authors declare no competing financial interest.

\section{ACKNOWLEDGMENTS}

We thank A. Kros and H. Wyss for essential discussions and $\mathrm{R}$. I. Koning and B. Koster for the cryo-TEM. C.Q.T. and T.X.L. thank the China Scholarship Council for their CSC scholarships. R.E.K. (NWO-ECHO-STIP Grant 717.014.005, NWOVENI Grant 722.012.011) and I.K.V. (NWO ECHO-STIP Grant 717.013.005, NWO VIDI Grant 723.014.006) thank The Netherlands Organisation for Scientific Research (NWO) for financial support.

\section{REFERENCES}

(1) Amabilino, D. B.; Smith, D. K.; Steed, J. W. Supramolecular materials. Chem. Soc. Rev. 2017, 46 (9), 2404-2420.

(2) Krieg, E.; Bastings, M. M.; Besenius, P.; Rybtchinski, B. Supramolecular polymers in aqueous media. Chem. Rev. 2016, 116 (4), 2414-2477.

(3) Aida, T.; Meijer, E.; Stupp, S. Functional supramolecular polymers. Science 2012, 335 (6070), 813-817.

(4) Webber, M. J.; Appel, E. A.; Meijer, E.; Langer, R. Supramolecular biomaterials. Nat. Mater. 2016, 15 (1), 13-26.

(5) Rudra, J. S.; Tian, Y. F.; Jung, J. P.; Collier, J. H. A self-assembling peptide acting as an immune adjuvant. Proc. Natl. Acad. Sci. U. S. A. 2010, 107 (2), 622-627.

(6) Stephanopoulos, N.; Freeman, R.; North, H. A.; Sur, S.; Jeong, S. J.; Tantakitti, F.; Kessler, J. A.; Stupp, S. I. Bioactive DNA-peptide nanotubes enhance the differentiation of neural stem cells into neurons. Nano Lett. 2015, 15 (1), 603-609.

(7) Hudalla, G. A.; Sun, T.; Gasiorowski, J. Z.; Han, H.; Tian, Y. F.; Chong, A. S.; Collier, J. H. Gradated assembly of multiple proteins into supramolecular nanomaterials. Nat. Mater. 2014, 13 (8), 829-836.

(8) Rodell, C. B.; Dusaj, N. N.; Highley, C. B.; Burdick, J. A. Injectable and Cytocompatible Tough Double-Network Hydrogels through Tandem Supramolecular and Covalent Crosslinking. Adv. Mater. 2016, 28 (38), 8419-8424.

(9) Bastings, M.; Koudstaal, S.; Kieltyka, R. E.; Nakano, Y.; Pape, A.; Feyen, D. A.; Van Slochteren, F. J.; Doevendans, P. A.; Sluijter, J. P.; Meijer, E.; Chamuleau, S. A. J.; Dankers, P. Y. W. A fast pH-switchable and self-healing supramolecular hydrogel carrier for guided, local catheter injection in the infarcted myocardium. Adv. Healthcare Mater. 2014, 3 (1), 70-78.

(10) Li, Y.; Khuu, N.; Gevorkian, A.; Sarjinsky, S.; Therien-Aubin, H.; Wang, Y.; Cho, S.; Kumacheva, E. Supramolecular Nanofibrillar Thermoreversible Hydrogel for Growth and Release of Cancer Spheroids. Angew. Chem. 2017, 129 (22), 6179-6183.

(11) Sinthuvanich, C.; Nagy-Smith, K. J.; Walsh, S. T.; Schneider, J. P. Triggered Formation of Anionic Hydrogels from Self-Assembling Acidic Peptide Amphiphiles. Macromolecules 2017, 50 (15), 56435651.
(12) Johnson, E. K.; Adams, D. J.; Cameron, P. J. Peptide based low molecular weight gelators. J. Mater. Chem. 2011, 21 (7), 2024-2027.

(13) Wang, Y.; Cheetham, A. G.; Angacian, G.; Su, H.; Xie, L.; Cui, $\mathrm{H}$. Peptide-drug conjugates as effective prodrug strategies for targeted delivery. Adv. Drug Delivery Rev. 2017, 110, 112-126.

(14) Ikonen, L.; Kerkelä, E.; Metselaar, G.; Stuart, M. C.; De Jong, M. R.; Aalto-Setälä, K. 2D and 3D self-assembling nanofiber hydrogels for cardiomyocyte culture. BioMed Res. Int. 2013, 2013, 1-12.

(15) Takahashi, K.; Tanabe, K.; Ohnuki, M.; Narita, M.; Ichisaka, T.; Tomoda, K.; Yamanaka, S. Induction of pluripotent stem cells from adult human fibroblasts by defined factors. Cell 2007, 131 (5), 861872.

(16) Yu, J.; Vodyanik, M. A.; Smuga-Otto, K.; Antosiewicz-Bourget, J.; Frane, J. L.; Tian, S.; Nie, J.; Jonsdottir, G. A.; Ruotti, V.; Stewart, R.; Slukvin, I. I.; Thomson, J. A. Induced pluripotent stem cell lines derived from human somatic cells. Science 2007, 318 (5858), 19171920.

(17) Higuchi, A.; Ling, Q. D.; Chang, Y.; Hsu, S. T.; Umezawa, A. Physical cues of biomaterials guide stem cell differentiation fate. Chem. Rev. 2013, 113 (5), 3297-3328.

(18) Higuchi, A.; Ling, Q. D.; Kumar, S. S.; Munusamy, M.; Alarfajj, A. A.; Umezawa, A.; Wu, G. J. Design of polymeric materials for culturing human pluripotent stem cells: Progress toward feeder-free and xeno-free culturing. Prog. Polym. Sci. 2014, 39 (7), 1348-1374.

(19) Higuchi, A.; Ling, Q. D.; Ko, Y. A.; Chang, Y.; Umezawa, A. Biomaterials for the feeder-free culture of human embryonic stem cells and induced pluripotent stem cells. Chem. Rev. 2011, 111 (5), 30213035.

(20) Peng, I. C.; Yeh, C. C.; Lu, Y. T.; Muduli, S.; Ling, Q. D.; Alarfaj, A. A.; Munusamy, M. A.; Kumar, S. S.; Murugan, K.; Lee, H. C.; Chang, Y.; Higuchi, A. Continuous harvest of stem cells via partial detachment from thermoresponsive nanobrush surfaces. Biomaterials 2016, 76, 76-86.

(21) Rosales, A. M.; Anseth, K. S. The design of reversible hydrogels to capture extracellular matrix dynamics. Nat. Rev. Mater. 2016, 1, 15012.

(22) Cosson, S.; Otte, E. A.; Hezaveh, H.; Cooper-White, J. J. Concise review: tailoring bioengineered scaffolds for stem cell applications in tissue engineering and regenerative medicine. Stem Cells Transl. Med. 2015, 4 (2), 156-164.

(23) Rehm, T.; Schmuck, C. How to achieve self-assembly in polar solvents based on specific interactions? Some general guidelines. Chem. Commun. 2008, 7, 801-813.

(24) Rao, K. V.; George, S. J. Supramolecular Alternate Co-Assembly through a Non-Covalent Amphiphilic Design: Conducting Nanotubes with a Mixed D-A Structure. Chem. - Eur. J. 2012, 18 (45), 1428614291.

(25) Krieg, E.; Weissman, H.; Shimoni, E.; Bar On, A.; Rybtchinski, $B$. Understanding the effect of fluorocarbons in aqueous supramolecular polymerization: ultrastrong noncovalent binding and cooperativity. J. Am. Chem. Soc. 2014, 136 (26), 9443-9452.

(26) Yu, Z.; Tantakitti, F.; Yu, T.; Palmer, L. C.; Schatz, G. C.; Stupp, S. I. Simultaneous covalent and noncovalent hybrid polymerizations. Science 2016, 351 (6272), 497-502.

(27) Appel, R.; Fuchs, J.; Tyrrell, S. M.; Korevaar, P. A.; Stuart, M. C.; Voets, I. K.; Schönhoff, M.; Besenius, P. Steric constraints induced frustrated growth of supramolecular nanorods in water. Chem. - Eur. J. 2015, 21 (52), 19257-19264.

(28) Rao, K. V.; Jayaramulu, K.; Maji, T. K.; George, S. J. Supramolecular Hydrogels and High-Aspect-Ratio Nanofibers through Charge-Transfer-Induced Alternate Coassembly. Angew. Chem. 2010, 122 (25), 4314-4318.

(29) Kluge, D.; Singer, J. C.; Neubauer, J. W.; Abraham, F.; Schmidt, H. W.; Fery, A. Influence of the Molecular Structure and Morphology of Self-Assembled 1, 3, 5-Benzenetrisamide Nanofibers on their Mechanical Properties. Small 2012, 8 (16), 2563-2570.

(30) Wilson, A. J. Non-covalent polymer assembly using arrays of hydrogen-bonds. Soft Matter 2007, 3 (4), 409-425. 
(31) Leenders, C. M.; Albertazzi, L.; Mes, T.; Koenigs, M. M.; Palmans, A. R.; Meijer, E. Supramolecular polymerization in water harnessing both hydrophobic effects and hydrogen bond formation. Chem. Commun. 2013, 49 (19), 1963-1965.

(32) Mes, T.; Cantekin, S.; Balkenende, D. W.; Frissen, M. M.; Gillissen, M. A.; De Waal, B. F.; Voets, I. K.; Meijer, E.; Palmans, A. R. Thioamides: versatile bonds to induce directional and cooperative hydrogen bonding in supramolecular polymers. Chem. - Eur. J. 2013, 19 (26), 8642-8649.

(33) Chebotareva, N.; Bomans, P. H.; Frederik, P. M.; Sommerdijk, N. A.; Sijbesma, R. P. Morphological control and molecular recognition by bis-urea hydrogen bonding in micelles of amphiphilic tri-block copolymers. Chem. Commun. 2005, 39, 4967-4969.

(34) Shimizu, L. S.; Hughes, A. D.; Smith, M. D.; Davis, M. J.; Zhang, B. P.; zur Loye, H.-C.; Shimizu, K. D. Self-assembled nanotubes that reversibly bind acetic acid guests. J. Am. Chem. Soc. 2003, 125 (49), 14972-14973.

(35) Li, A. F.; Wang, J. H.; Wang, F.; Jiang, Y. B. Anion complexation and sensing using modified urea and thiourea-based receptors. Chem. Soc. Rev. 2010, 39 (10), 3729-3745.

(36) Dingels, C.; Wurm, F.; Wagner, M.; Klok, H. A.; Frey, H. Squaric Acid Mediated Chemoselective PEGylation of Proteins: Reactivity of Single-Step-Activated $\alpha$-Amino Poly (ethylene glycol)s. Chem. - Eur. J. 2012, 18 (52), 16828-16835.

(37) Olmo, F.; Rotger, C.; Ramírez-Macías, I.; Martínez, L.; Marín, C.; Carreras, L.; Urbanová, K.; Vega, M.; Chaves-Lemaur, G.; Sampedro, A.; Rosales, M. J.; Sánchez-Moreno, M.; Costa, A. Synthesis and biological evaluation of $\mathrm{N}, \mathrm{N}^{\prime}$-squaramides with high in vivo efficacy and low toxicity: toward a low-cost drug against Chagas disease. J. Med. Chem. 2014, 57 (3), 987-999.

(38) Malerich, J. P.; Hagihara, K.; Rawal, V. H. Chiral squaramide derivatives are excellent hydrogen bond donor catalysts. J. Am. Chem. Soc. 2008, 130 (44), 14416-14417.

(39) Busschaert, N.; Kirby, I. L.; Young, S.; Coles, S. J.; Horton, P. N.; Light, M. E.; Gale, P. A. Squaramides as potent transmembrane anion transporters. Angew. Chem., Int. Ed. 2012, 51 (18), 4426-4430.

(40) Schiller, J.; Alegre-Requena, J. V.; Marqués-López, E.; Herrera, R. P.; Casanovas, J.; Alemán, C.; Díaz, D. D. Self-assembled fibrillar networks of a multifaceted chiral squaramide: supramolecular multistimuli-responsive alcogels. Soft Matter 2016, 12 (19), 43614374.

(41) Wu, D.; Jiang, R.; Luo, L.; He, Z.; You, J. Bromide aniontriggered visible responsive metallogels based on squaramide complexes. Inorg. Chem. Front. 2016, 3 (12), 1597-1603.

(42) Saez Talens, V.; Englebienne, P.; Trinh, T. T.; Noteborn, W. E.; Voets, I. K.; Kieltyka, R. E. Aromatic gain in a supramolecular polymer. Angew. Chem. 2015, 127 (36), 10648-10652.

(43) López, C.; Ximenis, M.; Orvay, F.; Rotger, C.; Costa, A. Supramolecular Hydrogels Based on Minimalist Amphiphilic Squaramide-Squaramates for Controlled Release of Zwitterionic Biomolecules. Chem. - Eur. J. 2017, 23 (31), 7590-7594.

(44) Noteborn, W. E.; Saez Talens, V.; Kieltyka, R. E. Reversible Loading of Nanoscale Elements on a Multicomponent Supramolecular Polymer System by Using DNA Strand Displacement. ChemBioChem 2017, 18 (20), 1995-1999.

(45) Storer, R. I.; Aciro, C.; Jones, L. H. Squaramides: physical properties, synthesis and applications. Chem. Soc. Rev. 2011, 40 (5), $2330-2346$

(46) Alemán, J.; Parra, A.; Jiang, H.; Jørgensen, K. A. Squaramides: bridging from molecular recognition to bifunctional organocatalysis. Chem. - Eur. J. 2011, 17 (25), 6890-6899.

(47) Cantekin, S.; de Greef, T. F.; Palmans, A. R. Benzene-1,3,5tricarboxamide: a versatile ordering moiety for supramolecular chemistry. Chem. Soc. Rev. 2012, 41 (18), 6125-6137.

(48) van Bommel, K. J.; van der Pol, C.; Muizebelt, I.; Friggeri, A.; Heeres, A.; Meetsma, A.; Feringa, B. L.; van Esch, J. Responsive Cyclohexane-Based Low-Molecular-Weight Hydrogelators with Modular Architecture. Angew. Chem., Int. Ed. 2004, 43 (13), 1663-1667.
(49) Ageitos, J. M.; Baker, P. J.; Sugahara, M.; Numata, K. Proteinase K-catalyzed synthesis of linear and star oligo (L-phenylalanine) conjugates. Biomacromolecules 2013, 14 (10), 3635-3642.

(50) Stanley, C. E.; Clarke, N.; Anderson, K. M.; Elder, J. A.; Lenthall, J. T.; Steed, J. W. Anion binding inhibition of the formation of a helical organogel. Chem. Commun. 2006, 30, 3199-3201.

(51) Hiscock, J. R.; Piana, F.; Sambrook, M. R.; Wells, N. J.; Clark, A. J.; Vincent, J. C.; Busschaert, N.; Brown, R. C.; Gale, P. A. Detection of nerve agent via perturbation of supramolecular gel formation. Chem. Commun. 2013, 49 (80), 9119-9121.

(52) Mukhopadhyay, S.; Maitra, U.; Krishnamoorthy, G.; Schmidt, J.; Talmon, Y. Structure and dynamics of a molecular hydrogel derived from a tripodal cholamide. J. Am. Chem. Soc. 2004, 126 (48), 1590515914.

(53) de Loos, M.; Ligtenbarg, A. G.; van Esch, J.; Kooijman, H.; Spek, A. L.; Hage, R.; Kellogg, R. M.; Feringa, B. L. Tripodal tris-urea derivatives as gelators for organic solvents. Eur. J. Org. Chem. 2000, 22, $3675-3678$

(54) Kremer, J. R.; Mastronarde, D. N.; McIntosh, J. R. Computer visualization of three-dimensional image data using IMOD. J. Struct. Biol. 1996, 116 (1), 71-76.

(55) Pettersen, E. F.; Goddard, T. D.; Huang, C. C.; Couch, G. S.; Greenblatt, D. M.; Meng, E. C.; Ferrin, T. E. UCSF Chimera-a visualization system for exploratory research and analysis. J. Comput. Chem. 2004, 25 (13), 1605-1612.

(56) Zhang, M.; D’Aniello, C.; Verkerk, A. O.; Wrobel, E.; Frank, S.; Ward-vanOostwaard, D.; Piccini, I.; Freund, C.; Rao, J.; Seebohm, G. Recessive cardiac phenotypes in induced pluripotent stem cell models of Jervell and Lange-Nielsen syndrome: disease mechanisms and pharmacological rescue. Proc. Natl. Acad. Sci. U. S. A. 2014, 111 (50), E5383-E5392.

(57) Orlova, V. V.; Van Den Hil, F. E.; Petrus-Reurer, S.; Drabsch, Y.; Ten Dijke, P.; Mummery, C. L. Generation, expansion and functional analysis of endothelial cells and pericytes derived from human pluripotent stem cells. Nat. Protoc. 2014, 9 (6), 1514-1531.

(58) Zhang, X.; Chu, X.; Wang, L.; Wang, H.; Liang, G.; Zhang, J.; Long, J.; Yang, Z. Rational Design of a Tetrameric Protein to Enhance Interactions between Self-Assembled Fibers Gives Molecular Hydrogels. Angew. Chem. 2012, 124, 4464-4468.

(59) Nebot, V. J.; Armengol, J.; Smets, J.; Prieto, S. F.; Escuder, B.; Miravet, J. F. Molecular Hydrogels from Bolaform Amino Acid Derivatives: A Structure-Properties Study Based on the Thermodynamics of Gel Solubilization. Chem. - Eur. J. 2012, 18 (13), 40634072.

(60) Yang, M.; Zhang, Z.; Yuan, F.; Wang, W.; Hess, S.; Lienkamp, K.; Lieberwirth, I.; Wegner, G. Self-Assembled Structures in Organogels of Amphiphilic Diblock Codendrimers. Chem. - Eur. J. 2008, 14 (11), 3330-3337.

(61) Caliari, S. R.; Burdick, J. A. A practical guide to hydrogels for cell culture. Nat. Methods 2016, 13 (5), 405-414.

(62) Caiazzo, M.; Okawa, Y.; Ranga, A.; Piersigilli, A.; Tabata, Y.; Lutolf, M. P. Defined three-dimensional microenvironments boost induction of pluripotency. Nat. Mater. 2016, 15 (3), 344-352.

(63) Kinney, M. A.; Saeed, R.; McDevitt, T. C. Mesenchymal morphogenesis of embryonic stem cells dynamically modulates the biophysical microtissue niche. Sci. Rep. 2015, 4, 4290.

(64) Kolahi, K. S.; Donjacour, A.; Liu, X.; Lin, W.; Simbulan, R. K.; Bloise, E.; Maltepe, E.; Rinaudo, P. Effect of Substrate Stiffness on Early Mouse Embryo Development. PLoS One 2012, 7 (7), e41717.

(65) Caliari, S. R.; Burdick, J. A. A practical guide to hydrogels for cell culture. Nat. Methods 2016, 13 (5), 405-414.

(66) Shin, D. S.; You, J.; Rahimian, A.; Vu, T.; Siltanen, C.; Ehsanipour, A.; Stybayeva, G.; Sutcliffe, J.; Revzin, A. Photodegradable hydrogels for capture, detection, and release of live cells. Angew. Chem., Int. Ed. 2014, 53 (31), 8221-8224.

(67) Lei, Y.; Schaffer, D. V. A fully defined and scalable 3D culture system for human pluripotent stem cell expansion and differentiation. Proc. Natl. Acad. Sci. U. S. A. 2013, 110 (52), E5039-E5048. 